\title{
Fruit Setting Behaviour of Passion Fruit
}

\author{
Mira Rani Das ${ }^{*}$, Tofazzal Hossain², M. A. Baset Mia², J. U. Ahmed ${ }^{2}$, A. J. M. Sirajul Karim³ \\ M. Mofazzal Hossain ${ }^{4}$

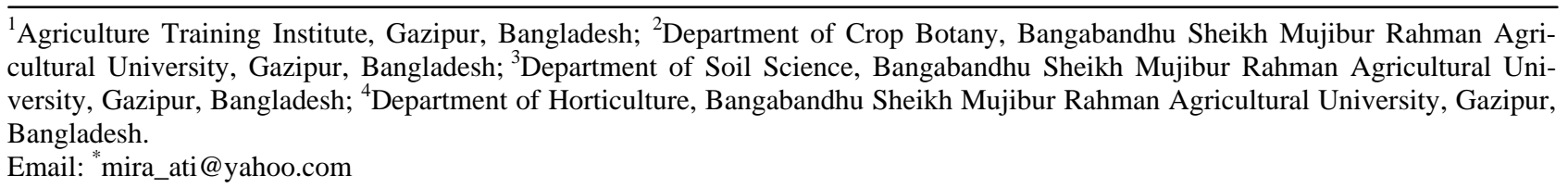

Received March $3^{\text {rd }}, 2013$; revised April 5 $5^{\text {th }}, 2013$; accepted May $15^{\text {th }}, 2013$

Copyright (c) 2013 Mira Rani Das et al. This is an open access article distributed under the Creative Commons Attribution License, which permits unrestricted use, distribution, and reproduction in any medium, provided the original work is properly cited.

\begin{abstract}
Passion fruit has great prospective to fascinate fruit consumer for its taste and delicious fruit juice and improvement of the economic condition of the fruit grower in the developing countries. The self-incompatibility in the passion fruits is an imperative reason to be considered regarding fruit production. Pollination is an essential for self-sterile crops as passion fruit (Passiflora edulis Sims.). The experiment was conducted in the field and laboratories of the Bangabandhu Sheikh Mujibur Rahman Agricultural University, Salna, Gazipur, Bangladesh to investigate the fruit setting behavior of passion fruits at during five flashes. We estimated to study fruit setting behavior of passion fruit at different flashes and determine effective pollination method and suitable flashes among five flashes. Result revealed that percent of fruit set of passion fruit was recorded highest; Seeds per plant were recorded highest in third flash when flowers were pollinated by hand compared with self-, and natural pollinations. Length-breadth ratios of fruits in third flashes were recorded higher when pollinates by hand. Individual fruit weight was also recorded higher at third flash. Plants required minimum days from flower anthesis to full maturity during third flash. On the other hand, fruit growth behavior of hand pollinated flowers was recorded higher during third flash of passion fruit. Results indicated that all studied characteristics of fruit and seed of passion fruit of third flash performed best.
\end{abstract}

Keywords: Passion Fruit; Fruit Setting; Flash; Pollination

\section{Introduction}

The passion fruit belongs to family passionflowers is an allogamous species [1]. In Passiflora genus contain more than 450 species but 12 species are cultivated. Only one species is Passiflora edulis Sims that grown as perennial, possess large flowers, and are cross-pollinated and vastly commercialized fruits [2]. It largely distributed around the tropics and warm humid subtropics [3-5]. It is an agronomically important delicious fruits [6] and cultivated for its ornamental, medicinal and nutritive characteristics [7]. Purple and yellow passion fruits are commonly cultivated in northern region of India [8].

Passion fruit has hermaphrodite, solitary flowers, located in the leaf axils. There are usually five stamens and ovary is borne over the androgynophore. There are three styles united at base, and at the top of style there are three bifurcated stigmas [9]. Passion fruits are protan-

\footnotetext{
"Corresponding author.
}

drous as anther dehiscence before stigma becomes receptive and stigma remains receptive from time of flower opening to closing. Rhythmic movement of the style of passion flower has been shown self-incompatibility because of the style is in upright position and it starts curving in due course of time. Due to it floral morphology yellow passion fruit is an allogamous plant and self-incompatibility of sporophytic type [10] and cultivated for its edible fruits [11]. Self-incompatibility is an important factor for passion fruit production [12].

Pollination is important for fruit production on passion vines and extent of fruit set is dependent on effective pollination. Many yellow passion fruits do not set fruit unless their flowers are dusted with pollen from a different vine that is genetically compatible. Hand pollination is the easiest way to ensure fruit production. Hand pollination increases fruit yield in passion fruit. Artificial pollination is necessary in passion fruit because of its floral morphology where the anthers placed bellow the stigma. 
Anther of passion fruit is versatile in nature and turns upside down at the time of anthesis. Pollen grains are large, highly sticky and self-incompatible. The self-incompatibility in the passion fruits is an important factor to be considered regarding fruit production and studies on the heredity [10,12].

The flowers of passion fruit are large, attractive, colorful and fragrant. The flowers produce a plenty of pollen and nectar that facilitate insect pollination. The principal insects visiting passion flower include Apis mellifera (honey bee) and Xylocopa vanpuncta (carpenter bees). Carpenter bee is most effective pollinator as it has large body and its body brushes along the anther and stigma while collecting nectar. On the other hand honey bees are not effective pollinator because of their foraging habit [13]. Though the passion flowers are hermaphrodite, they are self-sterile and self-incompatible which lead to poor fruit set [10]. The anther at the top of filament is versatile in nature. The anther just at the time anthesis turns upset down. The pollens of passion flower are very sticky in nature which may be another cause of poor fruit set naturally. Wind is ineffective for pollination because of heaviness and stickiness of the pollen though flowers have fertile pollen.

The passion flower usually opens around mid-day that is generally the warmest time of day, until the end of the afternoon. During this period pollinators collect nectar, transfer pollen from one flower to another. The effective pollination occurs in the period after the style curves completely [14].

Fruit setting behavior is an important criterion for plant breeder in the process of development of a variety. The development of variety has been associated with yield and fruit quality [15]. The agro-ecological conditions mainly of hill tract regions of Bangladesh are amiable for passion fruit cultivations [16]. Passion fruit in Bangladesh is grown popularly in home gardens for its lucrative color of flower and flavor and tasty yellow juice. Though the fruit setting behavior of passion fruit has been studied in details in other countries, very little work has been done in Bangladesh [16,17]. Due to above mentioned natural constraints pollination and fruit set of passion fruit is hampered. Considering the above facts the present study was undertaken to find out suitable pollination method for successful fruit setting.

\section{Materials and Methods}

The study was conducted at the experimental farm of Bangabandhu Sheikh Mujibur Rahman Agricultural University, Gazipur, situated at $24.09^{\circ}$ North latitude and $90.26^{\circ}$ East longitudes with an elevation of 8.4 meter from the sea level. The climate of experimental site is subtropical characterized by heavy rainfall during April to September and scanty during the rest of the year. Annual rainfall is favorable for passion fruit growing. The soil of the experimental field is clay loam in texture and acidic in nature with $\mathrm{pH}$ of around 5.8. The yellow passion fruit (Passiflora edulis Sims.) was used for the present experiment. Vine cuttings of two years old plant earlier collected from Bangladesh Agricultural Research Institute were used for the this study. Passion fruit were planted in trellised in rows $4.5 \mathrm{~m}$ apart and spaced $4.5 \mathrm{~m}$ apart within rows. The experimental plot was welldrained high land and where pit were prepared on the raised beds. Recommended fertilizers were applied in the pits $\left(50 \times 50 \times 50 \mathrm{~cm}^{3}\right) 10$ days before transplanting of cuttings. Flowers were pollinated by hand compared with self-, and natural pollinations.

Natural pollination: For natural pollination 100 well developed flower buds were tagged for each flash from healthy plants. At 15th day after tagging, fruits were counted. Natural pollination is usually caused by wind, water and insects.

Self-pollination: For self-pollination another 100 well developed flower buds were tagged and bagged from each flash on previous day of blooming from healthy plants. After 5 days the tags were removed. At 15th day after tagging, fruits were counted.

Hand Pollination: For hand pollination another 100 well developed flower buds were tagged from each flash on previous day of blooming from healthy plants. On next day the tagged well bloomed flowers were pollinated by hand. At 15th day after hand pollination fruits were counted.

Data on the Fruit weight, Fruit length, Fruit breadth, Fruit and seed setting and Number of seeds per fruits were recorded.

Fruit and seed setting after open-, self-, and hand pollination: Flowers tagged for natural, self- and hand pollination were done at different times of the day. Twenty flowers of each type were considered for each treatment. The flowers were bagged 24 hrs before anthesis and they were rebagged for another 5 days after pollination. Open pollinated flowers were only tagged. Fruit set was observed by counting the fruits harvested at maturity.

Number of seeds per fruits: To observe the seed setting ability of both types 40 - 45 days old fruits were harvested and numbers of seeds per fruit were counted. Total numbers of seeds per fruit were recorded.

The collected data were analyzed statistically using MSTAT-C computer package (Michigan State University, East Lansing, MI, USA) following the methods ofGomez and Gomez (1984) [18]. The analysis of variance procedure (ANOVA), differences among treatment means were determined using the Least Significant Difference (LSD) at $5 \%$ level of significance. 


\section{Results}

\subsection{Fruit Set}

Fruit set using three pollination methods at different flashes of passion fruit was described here.

\subsubsection{Self-Pollination}

Fruit set percent at different flashes using self-pollination ranged from $1.71 \%$ to $4.51 \%$ (Table 1 ). Plants produced maximum (4.51\%) fruit during third flash using selfpollination. Before and after third flash using self-pollination, fruit set percent was noticed to be declined gradually. Plants produced significantly higher fruits during third flash compared with other flashes using self-pollination. No significant change of fruit set was observed between third and fifth flashes using self-pollination.

\subsubsection{Natural Pollination}

At different flashes imposing natural pollination fruit set percent of passion fruit varied from 12.60 to 25.67. As self-pollination plants produced maximum fruit (25.67\%) during third flash imposing natural pollination (Table 1). Fruit set percent during third flash was recorded highest (25.67) compared with other flashes by natural pollination. Higher rate of fruit set of passion fruit was recorded in all flashes during natural pollination compared with self-pollination.

\subsubsection{Hand Pollination}

Among the studied methods, hand pollination showed to set highest percent of fruit at all flashes. Imposing hand pollination fruit set percent ranged from $31.61 \%$ to 46.71\% (Table 1). Among the three pollination methods, hand pollination was noticed to be best in respect of fruit set. As other two methods (self-pollination and natural pollination), hand pollination produced maximum fruit during third flash. Among the three pollination methods and five flashes, plant produced highest fruit imposing hand-pollination during third flash. Among the flashes, flowers pollinated by hand produced maximum fruits during third flash followed by fourth, second, fifth and first flashes.

\subsection{Seeds Per Fruit}

Effect of the pollination methods on seeds per fruit at different flashes was presented in Table 2.

\subsubsection{Self-Pollination}

Seeds per fruit in multiple seeded fruits depend upon number of pollens availability on the stigma of flower. Seeds per fruit of self-pollinated flower of passion fruit at different flashes were recorded variable. Seeds per fruit at different flashes ranged from 3.59 to 10.51 (Table 2). Seeds per fruit were recorded maximum (10.51) at third flashes followed by fourth, second, fifth and first flashes. From the finding it was noticed that imposing self-pol- lination early and late flowers produced minimum seeds per fruit.

\subsubsection{Natural Pollination}

From the findings it was observed that seeds per fruit imposing natural pollination at different flashes were recorded higher than that of self-pollination (Table 2). As self-pollination seeds per fruit in open pollinated flower at third flash were recorded maximum (16.51 seeds/fruit). The trend of seeds per fruit in open pollinated flowers at different flashes was noticed more or less as self-pollinated flowers. Seeds per fruit were recorded minimum (8.56) at fifth flash compared with self-pollination.

\subsubsection{Hand Pollination}

Among the three pollination methods, hand pollination produced maximum seeds per plant at all flashes (Table 2). It was recorded that among the three pollination methods and five flashes plant produced maximum seeds per fruit imposing hand-pollination at third flashes. Stigma of passion flower received maximum number of pollen which is the cause of maximum seeds per fruit. On the other hand, hot-humid weather was noticed favorable for better growth and development of passion fruit which prevailed during third flash. On the contrary average seeds per fruit imposing hand pollination were recorded maximum (Figure 1).

\subsection{Fruit Weight}

Effect of pollination methods on individual fruit weight (g) of passion fruit at different flashes at maturity on fresh weight basis was reported in Table 3.

\subsubsection{Self-Pollination}

Individual fruit weight of passion fruit at different flashes at maturity using self-pollination was noticed variable (Table 3). Individual fruit weight at different flashes ranged from 25.28 to $35.81 \mathrm{~g}$. Individual fruit weight was noticed maximum at third flash compared with other flashes. At first and fifth flashes individual fruit weight was recorded minimum as compared with other flashes imposing self-pollination.

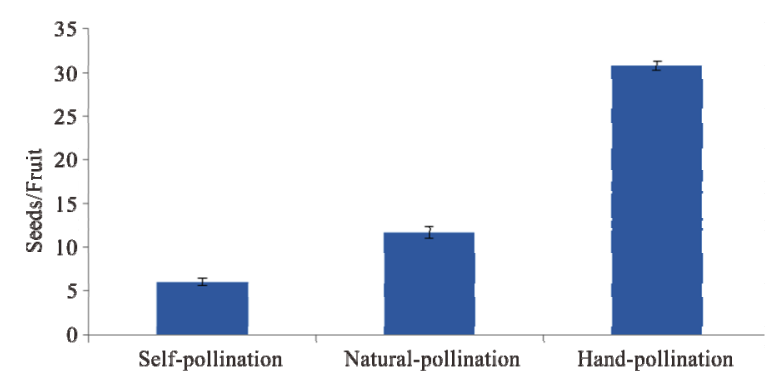

Figure 1. Effect of pollination methods on seeds per fruit (mean value). 
Table 1. Effect of pollination methods on fruit sets of passion fruit at different flashes (\%).

\begin{tabular}{ccccc}
\hline Flashes & Self-pollination & Natural-pollination & Hand-pollination & Mean \\
\hline First & $1.71 \mathrm{~d}$ & $15.50 \mathrm{c}$ & $31.61 \mathrm{~d}$ & 16.27 \\
Second & $2.16 \mathrm{c}$ & $20.45 \mathrm{~b}$ & $35.45 \mathrm{c}$ & 19.35 \\
Third & $4.51 \mathrm{a}$ & $25.67 \mathrm{a}$ & $46.71 \mathrm{a}$ & 25.63 \\
Fourth & $3.67 \mathrm{~b}$ & $15.18 \mathrm{c}$ & $40.12 \mathrm{~b}$ & 19.66 \\
Fifth & $1.90 \mathrm{~d}$ & $12.60 \mathrm{~d}$ & $32.15 \mathrm{~d}$ & 15.55 \\
Mean & 2.79 & 17.88 & 37.21 & 19.29 \\
\hline
\end{tabular}

Mean followed by same letter in the column are statistically similar

Table 2. Effect of pollination methods on seeds per fruit of passion fruit at different flashes (seeds/fruit).

\begin{tabular}{ccccc}
\hline Flashes & Self-pollination & Natural-pollination & Hand-pollination & Mean \\
\hline First & $3.59 \pm 0.76$ & $10.18 \pm 0.55$ & $30.64 \pm 0.47$ & $14.80 \pm 59$ \\
Second & $5.84 \pm 0.52$ & $12.25 \pm 0.63$ & $30.90 \pm 0.66$ & $16.33 \pm 0.60$ \\
Third & $10.51 \pm 0.67$ & $16.51 \pm 0.64$ & $35.18 \pm 0.52$ & $20.73 \pm 0.61$ \\
Fourth & $6.38 \pm 0.67$ & $10.91 \pm 0.76$ & $31.65 \pm 0.75$ & $16.31 \pm 0.73$ \\
Fifth & $4.12 \pm 0.66$ & $8.56 \pm 0.46$ & $25.68 \pm 0.66$ & $12.79 \pm 0.59$ \\
Mean & $6.09 \pm 0.66$ & $11.68 \pm 0.61$ & $30.81 \pm 0.63$ & $16.19 \pm 0.63$ \\
\hline
\end{tabular}

Table 3. Effect of pollination methods on individual fruit weight of passion fruit at different flashes at maturity on fresh weight basis (grams).

\begin{tabular}{cccc}
\hline Flashes & Self-pollination & Natural-pollination & Hand-pollination \\
\hline First & $26.42 \pm 0.57$ & $34.18 \pm 0.62$ & $30.41 \pm 0.65$ \\
Second & $32.91 \pm 0.51$ & $36.76 \pm 0.49$ & $33.56 \pm 0.62$ \\
Third & $35.81 \pm 0.54$ & $42.67 \pm 0.53$ & $39.40 \pm 0.66$ \\
Fourth & $33.95 \pm 0.56$ & $40.01 \pm 0.60$ & $35.63 \pm 0.40$ \\
Fifth & $25.28 \pm 0.44$ & $34.91 \pm 0.53$ & $31.18 \pm 0.62$ \\
Mean & 30.87 & 37.71 & 34.04 \\
\hline
\end{tabular}

\subsubsection{Natural Pollination}

Imposing natural pollination individual fruit weight of passion fruit at different flashes varied from 34.18 to 42.67 grams at maturity (Table 3 ). Results revealed that plant produced largest fruit (42.67 grams) using natural pollination followed by fourth, second, fifth and first flashes. As self-pollination, plant produced largest fruit during third flash imposing natural pollination. Compar- ing with self-pollination, individual fruit weight at dif- ferent flashes imposing natural pollination was recorded higher. Individual fruit weight is associated with the number of seeds per fruit. Fruit set of passion fruit was mainly caused by Apis mellifera (data not shown).

\subsubsection{Hand Pollination}

Individual fruit weight imposing hand pollination at different flashes ranged from 30.41 to 39.40 grams (Table 3). As self and natural pollinations, individual fruit weight at third flash was also recorded higher. Individual fruit weight of passion fruit at all flashes was noticed comparatively lower than natural pollination. Individual fruit weight depends upon number of fruits per plant. As fruit set it was higher imposing hand pollination. So the individual fruit weight was recorded comparatively lower than natural pollination.

Among the pollination methods at different flashes plant produced biggest fruit (42.67 g/fruit) during third flash pollinated with natural pollination. During third 
flash, plant showed vigorous growth which may be the cause of formation of longer fruit during third flash.

\subsection{Days Required from Anthesis to Maturity}

Fruit maturity of a crop is influenced by genetic make-up, physiological condition of the specific crop as well as environmental factors such as rainfall, humidity, temperature, day length etc. Fruit maturity of passion fruit at different flashes was noticed variable (Figure 2). Results revealed that plants required minimum days (42 days) from flower anthesis to full maturity during third flash. Days to maturity from anthesis was observed to be enhanced. On the other hand maturity of fruit was noticed to be delayed during first and fifth flashes of passion fruit. During third flash hot and humid weather as well as longest day-length prevailed that might be the cause of enhancement of fruit maturity.

\subsection{Fruit Length and Diameter}

Effect of pollination methods on fruit length and diameter of passion fruit at different flashes was presented in Table 4.

\subsubsection{Self-Pollination on Fruit Length}

Fruit length of passion fruit imposing self-pollination at different flashes was recorded not uniform (Table 4). Fruit length at different flashes ranged from 3.19 to 4.16 $\mathrm{cm}$. Fruit length was recorded maximum $(4.16 \mathrm{~cm})$ at third flash followed by fourth, second, fifth and first flashes. No significant change of fruit length between third and fourth flashes imposes self-pollination.

\subsubsection{Natural Pollination on Fruit Length}

Similar trend of fruit length at different flashes imposing natural pollination was noticed. But fruit length at all flashes was recorded little bigger than that of self-pollinated fruits. As self -pollination, plant produced longest fruits $(5.91 \mathrm{~cm})$ imposing natural pollination at third flash. Among the flashes, plant produced smallest fruit $(3.36 \mathrm{~cm})$ at first flash. Fruit length of passion fruit between third and fourth flashes did not show any signify- cant change.

\subsubsection{Hand Pollination on Fruit Length}

Plants produced longest fruit at all flashes imposing handpollination compared with self-and open pollinations. Plant produced longest fruit imposing hand pollination as self and open pollination at third flash (Table 4). Among these methods of pollination at different flashes plant showed longest fruit imposing hand pollination at third flash. Fruit length of multiple seeded fruit depends upon number seeds set in the fruit.

\subsection{Fruit Diameter}

Fruit diameter of passion fruit imposing self-, natural and hand pollinations at different flashes was mentioned in Table 4. No noticeable change of fruit diameter of passion fruit was observed imposing the above mentioned pollination methods during five flashes. Fruit diameter was affected by pollination methods and flashes.

\subsection{Length-Breadth Ratio}

Length-breadth ratio of passion fruit imposing different methods of pollination at different flashes was shown in Figure 3. It was noticed that length-breadth ratios of fruits of all flashes were recorded higher when passion flowers were pollinated by hand pollination followed by natural and self-pollinations.

\subsection{Fruit Yield}

Fruits per plant ranged from 2 to 28 by natural pollination. Plant produced maximal number of fruit by natural pollination during third flash. Minimal number of fruits per plant was noticed in fifth flash by natural pollination (Table 5). Fruit set percent at different flashes varied from 7.41 to 20.00 by natural pollination. As fruits per plant, fruit set percent was recorded highest at third flash. Fresh weight of individual fruit (g) was recorded maximum during third flash though it ranged from 21 to 34 by natural pollination.

Table 4. Effect of pollination methods on fruits length and diameter of passion fruit at different flashes on maturity (cm).

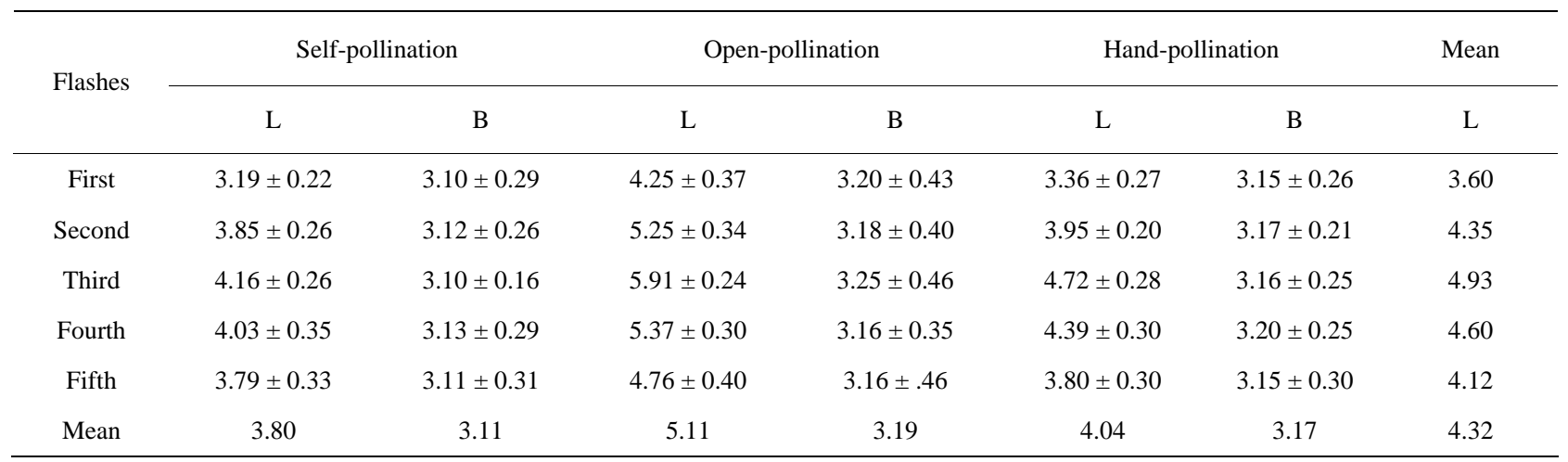


Table 5. Yield of passion fruit per plant by natural pollination.

\begin{tabular}{cccc}
\hline Flashes & Fruit set $\%$ & Fruit per plant & Fresh weight of individual fruit (g) \\
\hline First flash & $15.38 \mathrm{~b}$ & $8 \mathrm{~b}$ & $21 \mathrm{~b}$ \\
Second flash & $18.66 \mathrm{ab}$ & $25 \mathrm{a}$ & $31 \mathrm{a}$ \\
Third flash & $20.00 \mathrm{a}$ & $28 \mathrm{a}$ & $34 \mathrm{a}$ \\
Fourth flash & $17.24 \mathrm{ab}$ & $25 \mathrm{a}$ & $32 \mathrm{a}$ \\
Fifth flash & $7.41 \mathrm{c}$ & $2 \mathrm{c}$ & $23 \mathrm{~b}$ \\
\hline
\end{tabular}

Mean followed by same letter in the column are statistically similar

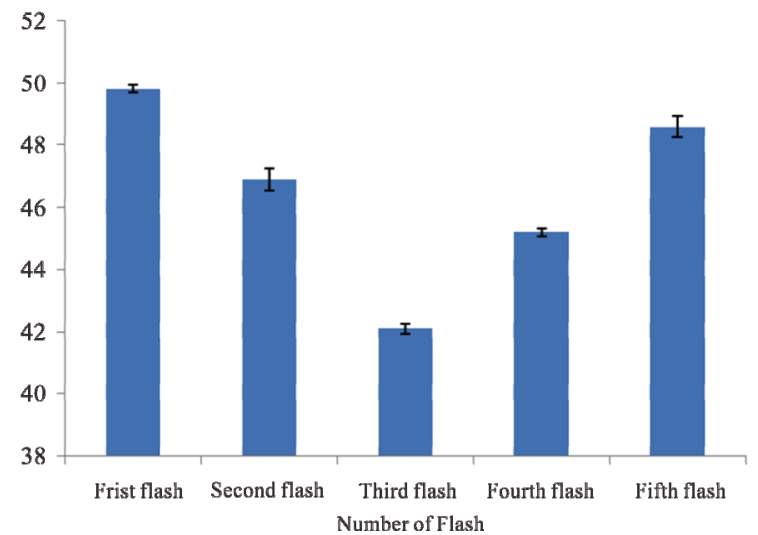

Figure 2. Effect of different flashes on days to fruit maturity from anthesis (days) of passion fruit.

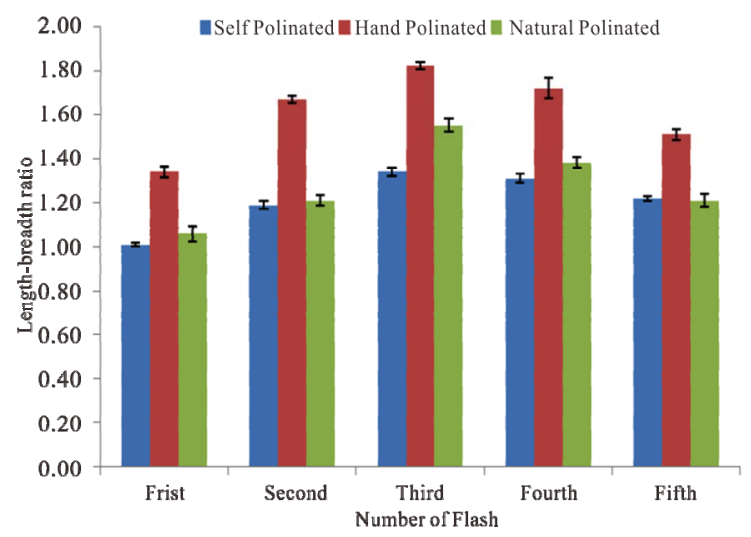

Figure 3. Length-breadth ratios at different flashes by applying different pollination.

\section{Discussion}

Pollination is an important criterion for fruit set in passion fruit. Our main aim was to determine the extent to which pollination methods are effective for successful fruit production. Kishore et al. (2010) [19] reported that maximum number of bees was observed between 07:00 08:00 $\mathrm{h}$ in purple and giant passion fruit, but between 13:00 - 14:00 $\mathrm{h}$ in yellow passion fruit. In the present study the maximum number of bees was noticed in the field during 13:00 - 14:00 h. For open pollination the most common pollinating bee for purple, giant and yel- low passion fruit was $A$. mellifera, while $A$. cerena was for $P$. foetida [19]. In this study Apis mellifera was noted the most common pollination bee.

Floral morphology of passion flower is the barrier for self-pollination due to pollen not reaching the stigma. Except self-pollination (0\% fruit set), manual pollination gave greater fruit set than natural pollination (about 55\% vs. $44.6 \%$ ), resulting in 90 -g fruits (20\% - 25\% heavier than those of the control). Juice percentage and seed number were increased by hand pollination by about 40 and $10 \%$. In general, cross pollinating at around $16.00 \mathrm{~h}$ gave the best results (Duarte and Sierra, 1997) [20] which was little contradictory with the present experiment. A high correlation between fruit weight and seed number, fruit length and diameter were noticed [21].

Though passion fruit ( $P$. edulis $f$. flavicarpa) is capable of a very small degree of self-compatibility, cross-pollination results in increased fruit set, fruit weight, seed set, juice volume and juice sugar concentration. Although large bees such as Xylocopa spp. were expected as pollinators, honeybees (A. mellifera) were the only pollinators observed. The foraging habits of honeybees, not their size, may cause less than expected percentage fruit set [13]. Fruit set of passion fruit in the present study in open pollinated flowers was caused mainly by honey bees (data were not shown) which was supported by Hammer (1987) [13].

Hand pollination alone or in combination with GA3 increased fruit set, fruiting and fruit quality (weight, juice weight and TSS) compared with open pollination. Hand pollinated fruits contained more seeds than open pollinated fruits. Hand pollination decreased rind weight and total acidity content [14]. Seeds per fruit by hand pollination in the present study were observed highest (35.18) compared with self- and natural pollinations which were supported by Saleh and Zarad (1996) [14].

Nazrul et al. (2003) [16] in yellow passion fruit reported $30 \%$ fruit set by hand pollination. In the present investigation, fruit set percent was recorded maximum (20) during third flash by natural pollination mainly caused by Apis mellifira. In another study, Kishore et al. (2010) [19] mentioned 42.2\% fruit set of yellow passion by using $A$. mellifera as a natural pollinator. Photoperiod 
[22], air temperature [23], pesticides [24] and soil moisture are factors that determine the yield of yellow passion fruit. Due to high humidity in anther opening time, cell content of pollen grain contain high osmotic pressure as well as low resistance of their walls, reduced pollen viability as a result affect the frutification and fertilization percentage in pollination [12]. Biotic factors such as the physiological stages of the plant interfere with the frutification and seed production [25]. The biochemical pathways that control fruit setting and maturity in yellow passionfruit [15]. The low yield before and after third flash is due to the lack of flowering and fructification of the plant because of climatic conditions. Flowering of third flash during June-July, that time cause of rainfall and high humidity temperature was relatively low in summer time. Relatively low temperatures are suitable for flowering and fruit set, and moderately high temperatures are favorable for fruit growth and quality in purple passion fruit [26].

\section{Conclusion}

Finally, it can be concluded that, among the pollination methods (self-, natural and hand pollination), passion fruit produced maximum fruits pollinating flowers by hand. Hand pollination showed maximum fruits per plant at all flashes. Seeds per plant were recorded highest when flowers are pollinated by hand. Individual fruit weight was recorded maximum with naturally pollinated flower. Plants required minmum period day from anthesis to full maturity at third flash compared with other flashes. Plants produced longest fruit by natural pollination followed by hand pollination during third flash.

\section{REFERENCES}

[1] W. B. Storey, "Chromosome Numbers of Some Species of Passiflora Occurring in Hawaii," Pacific Science, Vol. 4, No. 1, 1950, pp. 37-42.

[2] R. Yockteng, G. C. Eeckenbrugge and T. T. Souza-Chies, "Genomic and Breeding Resources," Wild Crop Relatives, 2011, pp. 129-171. doi:10.1007/978-3-642-20447-0_7

[3] J. Vanderplank, "Passion Flowers," MIT Press, Cambridge, 2000.

[4] T. Ulmer and J. MacDougal, "Passiflora: Passionflowers of the World,” Timber Press, Portland, USA, 2004.

[5] J. Morton, “Passion Fruit,” In: C. F. Dowling, Eds., Fruits of Warm Climates, Julia F. Morton, Miami, 1987, pp. 320-328.

[6] D. W. Turner, C. M. Menzel and D. R. Simpson, "Short Term Drying of Half the Root System Reduces Growth but Not Water Status or Photosynthesis in Leaves of Passion Fruit (Passiflora sp.)," Scientia Horticulturae, Vol. 65, No. 1, 1996, pp. 25-36.

[7] K. R. Shivanna, "Reproductive Assurance through Un- usual Autogamy in the Absence of Pollinators in Passiflora edulis (Passion Fruit),” Current Science, Vol. 103, No. 9, 2012, pp. 1091-1096

[8] K. Kishore, R. Bharali, K. A. Pathak and D. S. Yadav, "Studies on Ripening Changes in Purple Passion Fruit (Passiflora edulis Sims)," Journal of Food Science and Technology-Mysore, Vol. 43, No. 6, 2006, pp. 599-602.

[9] J. Vanderplank, "Passion Flowers,” MIT Press, UK, 1996.

[10] C. H. Bruckner, V. W. D. Casali Moaraes, A. J. Ragazzi and E. M. A. Silva, "Selfincompatibility in Passion Fruit (Passiflora edulis Sims),” Acta Horticulturae, Vol. 370, 1995, pp. 45-57. http://www.actahort.org

[11] M. M. Souza, T. N. S. Pereira, A. J. B. Dias, B. F. Ribeiro and A. P. Viana, "Structural, Hystochemical and Cytochemical Characteristics of the Stigma and Style in Passiflora edulis f. flavicarpa (Passifloraceae),” Braz. arch. biol.technol. Vol. 49, No. 1, 2006. doi:10.1590/S1516-89132006000100011

[12] M. M. Souza, A. P. Viana and T. N. S. Pereira, "A Putative Mutant of a Self-Compatible Yellow Passion Fruit with the Corona Color as a Phenotypic Marker," Bragantia, Vol. 69, No. 1, 2010. doi:10.1590/S0006-87052010000100003

[13] H. Hammer, "The Pollinators of the Yellow Passion Fruit Do They Limit the Success of Passiflora edulis f. flavicarpa as a Tropical Crop," Proceedings of the Florida State Horticultural Society, Vol. 100, 1987, pp. 283-287.

[14] A. M. Saleh and S. S. Zarad, "Effect of Hand Pollination and GA3 Application on Fruit Set, Fruiting and Fruit Quality of Passionfruit (Passiflora edulis)," Annals of Agricultural Science, Cairo, Vol. 41, 1996, pp. 303-312.

[15] M. F. Zerbini, W. C. Otoni and L. C. Vieira, "Compendium of Transgenic Crop Plants,” Passion Fruit, 2009. http://onlinelibrary.wiley.com

[16] M. I. Nazrul, M. M. Zaman, H. P. Mondal and M. Dhar, "Comparative Reproductive Biology of Passion Flower (Passiflora edulis Sims.),” Bangladesh Journal of Botany, Vol. 32, No. 2, 2003, pp. 95-99.

[17] M. B. Banu, M. Q. I. Matin, T. H. Hossain and M. M. Hoassain, "Flowering Behaviour, Flower Morphology of Passion Fruit (Passiflora edulis Sims.)," International Journal of Sustainable Crop Production, Vol. 4, No. 4, 2009, pp. 5-7.

[18] M. A. Gomez and A. A. Gomez, "Statistical Procedures for Agriculture Research,” 2nd Edition, John Wiley and Sons, New York, 1984, p. 640.

[19] K. Kishore, A. Pathak, R. Shukla and R. Bharali, "Study on Floral Biology of Passion Fruit (Passiflora spp.)," Pakistan Journal of Botany, Vol. 42, No. 1, 2010, pp. 2129. http://www.parc.gov.pk/NARC/narc.html

[20] O. Duarte and O. Sierra, "Effect of Hand Pollination on Yellow Passion Fruit (Passiflora edulis f. flavicarpa) in El Zamorano,” Proceedings of the Inter-American Society for Tropical Horticulture 43rd Annual Meeting, Guatemala City, 1997.

[21] M. M. Souza, T. N. S. Pereira, A. P. Viana, M. G. Pereira, A. T. do Amaral Jr. and H. C. Madureira, "Flower Recep- 
tivity and Fruit Characteristics Associated to Time of Pollination in the Yellow Passion Fruit Passiflora edulis Sims f. flavicarpa Degener (Passifloraceae)," Scientia Horticulturae, Vol. 101, No. 4, 2004, pp. 373-385. doi:10.1016/j.scienta.2003.11.020

[22] J. C. Cavichioli, C. Ruggiero, C. A. Volpe, E. M. Paulo, J. L. Fagundes and F. S. Kasai, "Flowering and Fructification of Yellow Passion Fruit Submitted to Artificial Light, Irrigation and Shade," Revista Brasileira de Fruticultura, Vol. 28, No. 1, 2006, pp. 92-96. doi:10.1590/S0100-29452006000100026

[23] G. F. Iapichino and J. B. Loy, "High Temperature Stress Affects Pollen Viability in Bottle Gourd," Journal of the American Society for Horticultural Science, Vol. 112, 1987, pp. 372-374. http://www.nal.usda.gov/
[24] M. M. Silva, C. H. Bruckner, M. Picanco and A. J. M. Rugama, "Number of Flowers, Climate, Population Density of Xylocopa spp. (Hymenoptera: Anthophoridae) and Pollination of Passionflower," Revista de Biologia Tropical, Vol. 47, No. 4, 1999, pp. 711-718.

[25] I. E. Lederman, "The Involvement of Ethylene in Fruit Development, Maturation and Ripening of the Passion Fruit, Passiflora edulis Sims,” The Hebrew University of Jerusalem, Jerusalem, 1987, p. 280.

[26] N. Utsunomiya, "Effect of Temperature on Shoot Growth, Flowering and Fruit Growth of Purple Passionfruit (Passiflora edulis Sims var. edulis)," Scientia Horticulturae, Vol. 52, No. 1-2, 1992, pp. 63-68.

doi:10.1016/0304-4238(92)90008-Z 